\title{
Corrosion inhibition studies of new synthesized 1,4-dioctyl-6- methyl-1,4-dihydroquinoxaline-2,3-dione on mild steel in 1.0 M HCl solution using gravimetric and electrochemical techniques supported by theoretical DFT calculations
}

\section{A. Zouitini, ${ }^{1}$ Y. Kandri Rodi, ${ }^{1}$ Y. Ouzidan, ${ }^{1}$ F. Ouazzani Chahdi, ${ }^{1}$ M. Mokhtari, ${ }^{2}$ I. Abdel-Rahman, ${ }^{3}$ E.M. Essassi, ${ }^{4}$ A. Aouniti, ${ }^{5}$ B. Hammouti ${ }^{5}$ and H. Elmsellem ${ }^{*}$}

${ }^{1}$ Laboratory of Applied Organic Chemistry, Faculty of Science and Technology, University Sidi Mohammed Ben Abdallah, Fez, Morocco

${ }^{2}$ Laboratory of Valorization and Technology of Saharian Resources (VTRS), Faculty of Technology, Hamma Lakhdar University, 39000, Algeria

${ }^{3}$ Department of Chemistry, College of Sciences, University of Sharjah, PO Box: 27272, $U A E$

${ }^{4}$ Laboratoire de Chimie Organique Hétérocyclique, URAC 21, Pôle de Compétences Pharmacochimie, Université Mohammed V, Faculté des Sciences, Av. Ibn Battouta, BP 1014 Rabat, Morocco

${ }^{5}$ Laboratory of Analytical Chemistry, Materials, and Environment (LC2AME), Faculty of Sciences, University of Mohammed Premier, B.P. 717, 60000 Oujda, Morocco *E-mail: h.elmsellem@gmail.com

\begin{abstract}
The inhibition performance of 1,4-dioctyl-6-methyl-1,4-dihydroquinoxaline-2,3-dione (AY15) was studied as an inhibitor of mild steel in $1.0 \mathrm{M} \mathrm{HCl}$ solution at $308 \mathrm{~K}$ using experimental methods and theoretical calculations. 1,4-dioctyl-6-methyl-1,4-dihydroquinoxaline-2,3-dione (AY15) was synthesized and identified by elemental analysis, IR, ${ }^{1} \mathrm{H}$ NMR and ${ }^{13} \mathrm{C}$ NMR spectroscopy. The corrosion inhibition of (AY15) in $1.0 \mathrm{M} \mathrm{HCl}$ solution for mild steel was evaluated using weight loss and electrochemical techniques. The weight loss results show that inhibition efficiency increasing with increasing AY15 concentration and maximum value was obtained at $10^{-3} \mathrm{M}$ concentration. Polarization analysis suggests that compound act as a mixed type of inhibitor. EIS data showed that in the presence of inhibitor, transfer resistance increased and $C_{\mathrm{dl}}$ decreased due adsorption of inhibitor at the metal surface. It was found also that the adsorption of the inhibitor on the mild steel surface obeys the Langmuir isotherm model. The weight loss, electrochemical and Density Functional Theory (DFT) calculations are in good agreement.
\end{abstract}

Key words: mild steel, electrochemistry, weight loss, inhibitor, theoretical investigation. 


\section{Introduction}

In organic chemistry, nitrogen-containing heterocycles are indispensable structural units for medicinal activities. Quinoxalines represent an important class of heterocyclic compounds, they form an important biologically active molecules as there are various antibiotics such as hinomycin and levomycin, and actinoleutin [1,2]. Quinoxaline derivatives have been reported to exhibit various biological activities including antidiabetic [3], antibacterial [4], anticancer [5], and antifungal [6] activities.

Improved properties of mild steel (MS), such as high strength, hardness, flexibility and cost reduction, make the mild steel a raw material in various industrial divisions [7]. In fact, MS deserves to be individual due to its availability that makes most of the metals were made from MS base [8]. Today, these metals suffer grave damage in manufacturing parks when they are exposed to attack, descaling or cleaning processes by different aggressive acids. This is predictable and costly. In order to minimize environmental problems and cost, it is essential to synthesize new environmentally friendly organic compounds as corrosion inhibitors that reducing the rate of corrosion [9]. The addition of an inhibitor is one of the least expensive methods that have been used for this purpose. Many researchers have tried to synthesize inhibitors by adopting a variety of methodologies to obtain new organic and inorganic compounds [10].

Several types of organic compounds been used as successful corrosion inhibitors for MS [11].

The organic inhibitors like quinoxalines inhibit the corrosion of metals to a certain extent which depend mainly on their structure and the number of the heteroatoms that present in the compounds such as nitrogen, sulfur or/and oxygen. Recent investigations were also published about the usage of quinoxalines as inhibitors [12].

In this work the corrosion inhibition effect of 1,4-dioctyl-6-methyl-1,4dihydroquinoxaline-2,3-dione (AY15) on mild steel in $1.0 \mathrm{M} \mathrm{HCl}$ solution was studied. Gravimetric, electrochemical impedance spectroscopy (EIS) and potentiodynamic polarization techniques were used in this study. Quantum calculations for AY15 was estimated using density functional theory (DFT).

\section{Materials and solutions}

\section{Synthesis of inhibitor}

The synthesis of compound AY15 is carried out according to the reaction scheme below:

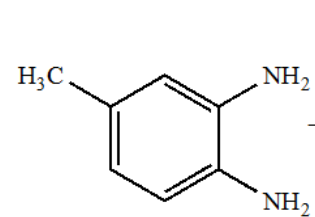

(1)

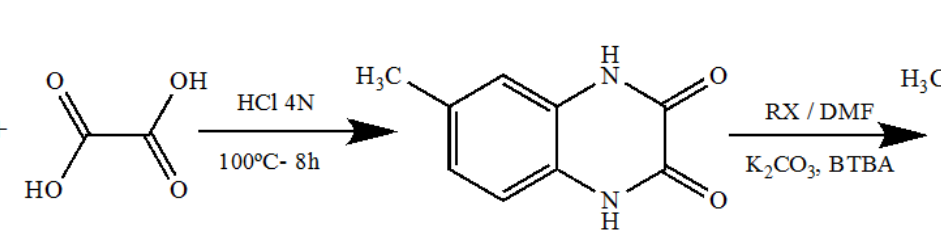

(2)
(3)

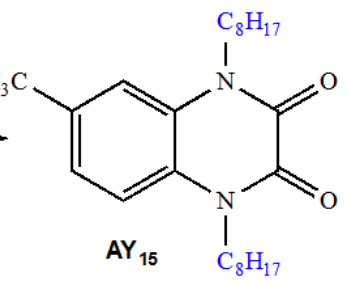

Scheme 1 
Synthesis of 6-methyl-1,4-dihydroquinoxaline-2,3-dione (3)

Oxalic acid (2) (8 mmol) was added to a solution of 4-methyl-o-phenylenediamine (1) $(8 \mathrm{mmol})$ in $16 \mathrm{ml}$ of hydrochloric acid $(4 \mathrm{M})$. The mixture was refluxed for 4 hours. The black precipitate that formed $\mathbf{3}$ was washed several times with distilled water.

6-Methyl-1,4-dihydroquinoxaline-2,3-dione (3)

Yield: (90\%); Mp: $361^{\circ} \mathrm{C} ;{ }^{1} \mathrm{H}$ NMR (DMSO-d $\left.{ }_{6}\right) \delta: 2.26$ (s, 3H, $\left.\boldsymbol{C H}_{3}\right) ; 6.87-7.28(\mathrm{~m}, 3 \mathrm{H}$, $\left.\mathrm{CH}_{\text {arom }}\right) ; 11.83(\mathrm{~s}, 2 \mathrm{H}, 2 \mathrm{NH}),{ }^{13} \mathrm{C}$ NMR $\left(\mathrm{DMSO}_{6}\right) \delta$ : $155.76(\boldsymbol{C}=\mathrm{O}) ; 155.44(\boldsymbol{C}=\mathrm{O})$; $132.73(\boldsymbol{C q}) ; 125.92(\boldsymbol{C q}) ; 124.23\left(\boldsymbol{C} \mathrm{H}_{\text {arom }}\right) ; 123.76(\boldsymbol{C q}) ; 115.61\left(\boldsymbol{C} \mathrm{H}_{\text {arom }}\right) ; 115.44\left(\boldsymbol{C} \mathrm{H}_{\text {arom }}\right)$; $21.01\left(\mathrm{CH}_{3}\right)$.

Synthesis of quinoxaline derivative (AY15)

Potassium carbonate $(3.61 \mathrm{mmol})$ and tetra- $n$-butyl ammonium (BTBA) $(0.1 \mathrm{mmol})$ were added to a solution of 6-methyl-1,4-dihydroquinoxaline-2,3-dione $3(1.73 \mathrm{mmol})$ in $20 \mathrm{ml}$ of DMF. The mixture was stirred for 10 minutes. After that, 1-bromo-octane $(3.46 \mathrm{mmol})$ was added and the reaction mixture was stirred for another 12 hours at room temperature. The reaction mixture was filtered and the DMF solvent was evaporated under reduced pressure. The obtained residue was dissolved in dichloromethane and dried using $\mathrm{Na}_{2} \mathrm{SO}_{4}$ as drying agent. The final product separated using silica gel column chromatography with an eluent volume ratio of (5/1) hexane/ethyl acetate.

\section{1,4-Dioctyl-6-methyl-1,4-dihydroquinoxaline-2,3-dione (AY15)}

Yield: (89\%); Mp: $118.3{ }^{\circ} \mathrm{C} ;{ }^{1} \mathrm{H}$ NMR $\left(\mathrm{CDCl}_{3}\right) \delta$ (Figure 1): $0.88\left(\mathrm{~m}, 6 \mathrm{H}, 2 \mathrm{CH}_{3}\right) ; 1.37-$ $1.46\left(\mathrm{~m}, 20 \mathrm{H}, 10 \mathrm{CH}_{2}\right) ; 1.69-1.80\left(\mathrm{~m}, 4 \mathrm{H}, 2 \mathrm{CH}_{2}\right) ; 2.44\left(\mathrm{~s}, 3 \mathrm{H}, \mathrm{CH}_{3}\right) ; 4.15-4.21(\mathrm{~m}, 4 \mathrm{H}$, $\left.2 \mathrm{CH}_{2}\right) ; 6.77-7.15\left(\mathrm{~m}, 3 \mathrm{H}, \mathrm{CH}_{\text {arom }}\right) ;{ }^{13} \mathrm{C} \mathrm{NMR}\left(\mathrm{CDCl}_{3}\right) \delta$ (Figure 2): $154.12(\boldsymbol{C}=\mathrm{O}) ; 153.87$ $(\boldsymbol{C}=\mathrm{O}) ; 133.93(\boldsymbol{C q}) ; 126,59(\boldsymbol{C q}) ; 124.73\left(\boldsymbol{C} \mathrm{H}_{\text {arom }}\right) ; 124.44(\boldsymbol{C q}) ; 115.49\left(\boldsymbol{C} \mathrm{H}_{\text {arom }}\right) ; 114.99$ $\left.\left(\boldsymbol{C} \mathrm{H}_{\text {arom }}\right) ; 43.15\left(\boldsymbol{C H _ { 2 }}\right) ; 43.06\left(\boldsymbol{C H}_{2}\right) ; 31.78\left(\boldsymbol{C H}_{2}\right) ; 29.29(\boldsymbol{C H})_{2}\right) ; 29.25\left(\boldsymbol{C H}_{2}\right) ; 29.16\left(2 \boldsymbol{C H}_{2}\right)$; $26.92\left(2 \boldsymbol{C H}_{2}\right) ; 26.89\left(\boldsymbol{C H}_{2}\right) ; 26.86\left(\boldsymbol{C H}_{2}\right) ; 26.80\left(\boldsymbol{C H}_{2}\right) ; 22.65\left(\boldsymbol{C H}_{2}\right) ; 21.24\left(\boldsymbol{C H}_{3}\right) ; 14.11$ $\left(2 \mathrm{CH}_{3}\right)$.

\section{Materials and solutions}

The mild steel (MS) specimens having the following chemical composition (wt. \%): C $0.076 \%$, Si $0.026 \%$, Mn 0.192 \%, P 0.012\%, Cr 0.050\%, Ni 0.050\%, Al 0.023\%, Cu $0.135 \%$ and $\mathrm{Fe} 99.30 \%$ were used for gravimetric and electrochemical experiments. The specimens with dimensions $1.5 \mathrm{~cm} \times 1.5 \mathrm{~cm} \times 0.05 \mathrm{~cm}$ were used for gravimetric test. The mild steel specimens were abraded by silicon carbide $(\mathrm{SiC})$ abrasive papers (from grade 600 to 1200), rinsed with distilled water and finally degreased by acetone. The $1.0 \mathrm{M} \mathrm{HCl}$ solutions were prepared by diluting the analytical grade hydrochloric acid solution $(\mathrm{HCl}$, $37 \%$, Fisher Scientific) with double distilled water. 


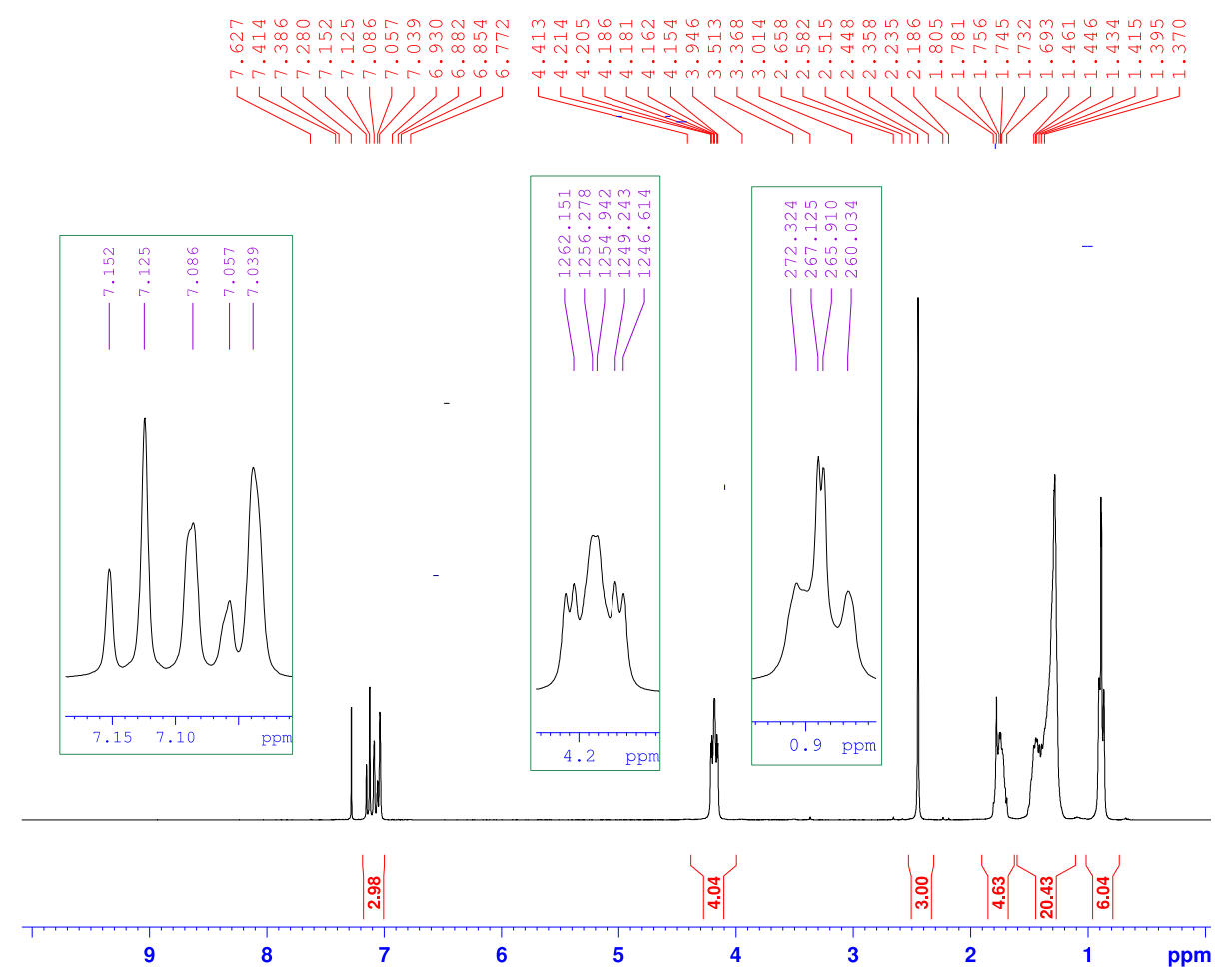

Figure 1. ${ }^{1} \mathrm{H}$ NMR spectrum of 1,4-dioctyl-6-methyl-1,4-dihydroquinoxaline-2,3-dione (AY15).

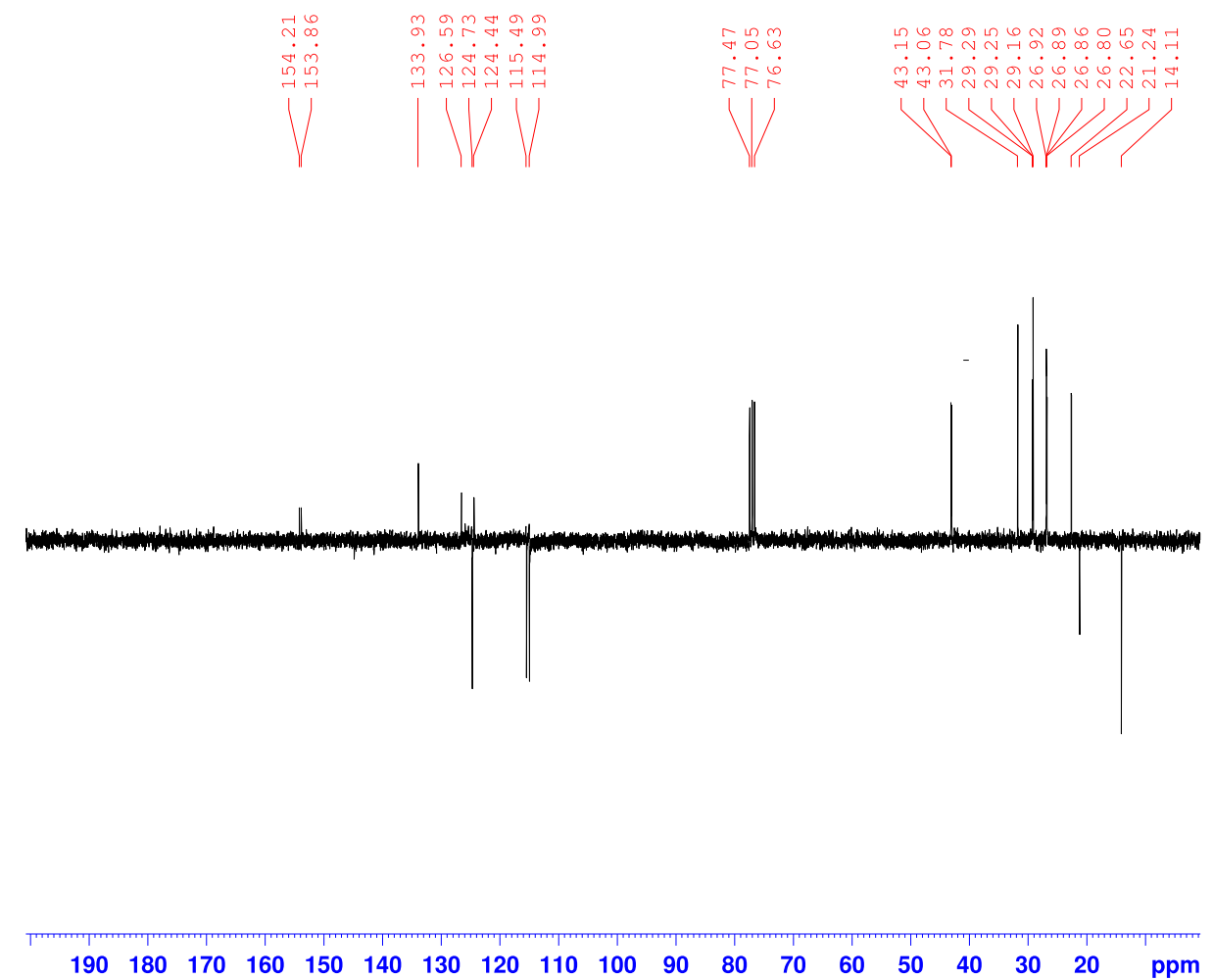

Figure 2. ${ }^{13} \mathrm{C}$ NMR spectrum of 1,4-dioctyl-6-methyl-1,4-dihydroquinoxaline-2,3-dione (AY15). 


\section{Polarization measurements}

The electrochemical study was carried out using a potentiostat PGZ100 piloted by Voltamaster software. This potentiostat was connected to a cell with three electrodes thermostat with double wall. A saturated calomel electrode (SCE) and platinum electrode were used as reference and auxiliary electrodes, respectively. Anodic and cathodic potentiodynamic polarization curves were plotted at a polarization scan rate of $0.5 \mathrm{mV} / \mathrm{s}$. Before all experiments, the potential was stabilized at free potential for 30 minutes. The polarization curves are obtained from $-800 \mathrm{mV}$ to $-200 \mathrm{mV}$ at $308 \mathrm{~K}$. The test solution was there after de-aerated by bubbling with nitrogen gas. The inhibition efficiency $\left(E_{\mathrm{I}} \%\right)$ was obtained using the following equation [13]:

$$
E_{\mathrm{I}} \%=\left(1-\frac{I_{\text {corr }}}{I_{\text {corr }}^{0}}\right) \times 100,
$$

where $I_{\text {corr }}^{0}$ and $I_{\text {corr }}$ are the uninhibited and inhibited corrosion current densities, respectively.

\section{Impedance measurements}

The electrochemical impedance spectroscopy (EIS) measurements are carried out using the electrochemical system with a digital potentiostat model Voltalab PGZ100 computer at $E_{\text {corr }}$ after immersion in $1.0 \mathrm{M} \mathrm{HCl}$ solution without bubbling of nitrogen gas. After the determination of steady-state current at a corrosion potential, sine wave voltage $(10 \mathrm{mV})$ peak to peak, at frequencies between $100 \mathrm{kHz}$ and $10 \mathrm{mHz}$ are superimposed on the rest potential. Computer programs automatically controlled the measurements performed at rest potentials after 0.5 hour of exposure at $308 \mathrm{~K}$. The impedance diagrams are given in the Nyquist representation. Inhibition efficiency $\left(E_{\mathrm{EIS}} \%\right)$ is estimated using the relation (2), [14].

$$
E_{\mathrm{EIS}} \%=\left(R_{\mathrm{ct}}-R_{\mathrm{ct}}^{0}\right) \times 100,
$$

where $R_{\mathrm{ct}}^{0}$ and $R_{\mathrm{ct}}$ are the charge transfer resistance values in the absence and presence of inhibitor, respectively.

\section{Results and Discussion}

\subsection{Corrosion inhibition evaluation}

\subsubsection{Gravimetric measurements}

Weight loss measurements are carried out using MS specimens immersed in $1.0 \mathrm{M} \mathrm{HCl}$ solutions in the absence and presence of different concentrations of the inhibitor AY15 $\left(10^{-6}-10^{-3} \mathrm{M}\right)$.

The inhibition efficiency $\left(E_{\mathrm{I}} \%\right)$ and the surface coverage $(\theta)$ values are presented in Table 1. It is observed clearly that the inhibition efficiency and the surface coverage values 
increases with the increase in the concentration of the inhibitor AY15. This means that the inhibitor was adsorbed on the MS surface and so it decreases its rate of corrosion [38].

Maximum inhibition was obtained $(93 \%)$ for AY15 at $10^{-3} \mathrm{M}$. This can be attributed to the presence of nitrogen and oxygen hetero atoms, bulky structure with large surface area and aromaticity which can involve $\pi$-electrons cloud that can interact with the metal surface by creating a better surface coverage.

Table 1. The corrosion rate, the corrosion inhibition efficiency and the surface coverage values of MS in $1.0 \mathrm{M} \mathrm{HCl}$ solutions in the absence and presence of AY15 inhibitor.

\begin{tabular}{ccccc}
\hline $\begin{array}{c}\text { Inhibitor } \\
\text { in 1.0 M HCl }\end{array}$ & $\boldsymbol{C}(\mathbf{m o l} / \mathbf{l})$ & $\boldsymbol{W}\left(\mathbf{m g} \cdot \mathbf{c m}^{-2} \cdot \mathbf{h}^{-\mathbf{1}}\right)$ & $\boldsymbol{E}_{\mathbf{w}}(\boldsymbol{\%})$ & $\boldsymbol{\theta}$ \\
\hline- & - & 0.82 & - & - \\
\hline & $10^{-6}$ & 0.29 & 65 & 0.65 \\
\multirow{2}{*}{ AY15 } & $10^{-5}$ & 0.21 & 74 & 0.74 \\
& $10^{-4}$ & 0.13 & 84 & 0.84 \\
& $10^{-3}$ & 0.06 & 93 & 0.93 \\
\hline
\end{tabular}

\subsubsection{Adsorption isotherm and thermodynamic parameters}

The adsorption of inhibitor AY15 on the MS surface can be assessed by fitting the experimental data obtained from gravimetric method with various adsorption isotherms. The best fit was found with Langmuir adsorption isotherm $(C / \theta$ vs $C)$ as shown in Figure 3. It is represented by the following equation [15]:

$$
\frac{C}{\theta}=\frac{1}{K_{a d s}}+C,
$$

where $C$ is the concentration of AY15 inhibitor, $K_{\mathrm{ads}}$ is the adsorption equilibrium constant, and $\theta$ is the surface coverage. The regression coefficient $R^{2}$ is represented in Table 2 and the value is so close to unity validating Langmuir adsorption isotherm. This model assumes that the solid surface contains a fixed number of adsorption sites and each siteholds one adsorbent revealing monolayer adsorption [16].

The large $K_{\text {ads }}$ value $\left(2.17 \cdot 10^{5}\right)$, Table 2 , reflects an efficient adsorption of AY15 inhibitor on the MS surface and high corrosion inhibition efficiency of this inhibitor $[17,18]$.

The equilibrium constant for the adsorption-desorption process is related to the standard free energy of adsorption $\Delta G_{\text {ads }}$ according to the following relation [19]:

$$
\Delta G_{\text {ads }}=-R T \ln (55.5 K),
$$

where $R$ is the universal gas constant and $T$ is the absolute temperature. 
Moreover the type of adsorption process taking place on the electrode surface can be justified by the value of $\Delta G_{\mathrm{ads}}^{0}$. The negative value of free energy of adsorption $\left(\Delta G_{\mathrm{ads}}^{0}\right)$ indicates the spontaneous adsorption of AY15 inhibitor on the MS surface. This value is close to $-40 \mathrm{~kJ} \mathrm{~mol}^{-1}$, Table 2 , which means that the type of adsorption is predominantly chemisorption [20, 21].

Table 2. Langmuir adsorption isotherm parameters for $\mathrm{MS}$ in $1.0 \mathrm{M} \mathrm{HCl}$ solutions without and with different concentrations of AY15 inhibitor at $308 \mathrm{~K}$.

\begin{tabular}{cccc}
\hline Inhibitor & $\boldsymbol{R}^{\mathbf{2}}$ & $\boldsymbol{K}_{\text {ads }}\left(\mathbf{k M}^{\mathbf{- 1}}\right)$ & $-\boldsymbol{\Delta} \boldsymbol{G}_{\text {ads }} \mathbf{~ k J ~ m o l}^{-\mathbf{1}}$ \\
\hline AY15 & 0.99992 & $2.17 \mathrm{E}+05$ & 41.74 \\
\hline
\end{tabular}

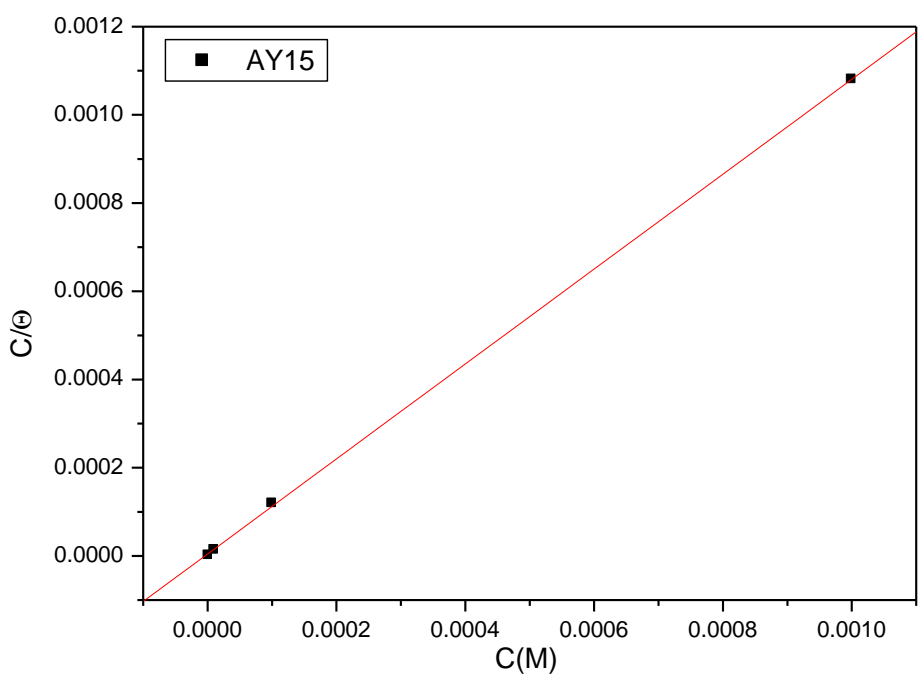

Figure 3. Langmuir adsorption plot for MS in $1.0 \mathrm{M} \mathrm{HCl}$ solutions without and with different concentrations of AY15 inhibitor.

\subsection{Electrochemical measurements}

\subsubsection{Tafel plots measurements}

The following polarization parameters results: Tafel slopes $\left(\beta_{\mathrm{c}}\right)$, corrosion current $\left(I_{\text {corr }}\right)$ and corrosion potential $\left(E_{\text {corr }}\right)$ are listed in Table 3.

In general, acidic medium is associated with the anodic corrosion reaction with the passage of metal ions in to the solution and the cathodic reaction by means of discharge of $\mathrm{H}_{2}$ gas. It was clearly noticed that the $I_{\text {corr }}$ values of the MS in the uninhibited solution $\left(1386 \mu \mathrm{A} / \mathrm{cm}^{2}\right)$ decreased successively by the addition of inhibitor AY15, indicating that the corrosion process of MS is considerably reduced due to the formation of a protective barrier on the metal surface [22]. 
The corrosion inhibition efficiency of any inhibitor predominantly depends on the presence of functional groups, heteroatoms like $\mathrm{O}, \mathrm{N}, \mathrm{S}$ and its molecular structure [23]. In this study AY15 inhibitor revealed a high corrosion inhibition efficiency due to the presence of $\mathrm{O}$ and $\mathrm{N}$ atoms, aromatic bi-electrons and structure bulkiness.

Low corrosion current densities values indicate that the rate of corrosion is very low. Minimum changes observed in the Tafel slopes show that there is a minimum change in the metal dissolution mechanism. From Figure 4, it is obviously seen that the addition of AY15 inhibitor affects both the cathodic and anodic curves. In addition the displacement in $E_{\text {corr }}$ value [24] was found to be $21 \mathrm{mV}$ in case of AY15 which is obviously less than $85 \mathrm{mV}$, suggesting mixed type of inhibition. This means a reduction of both anodic metal dissolution and cathodic hydrogen gas evolution. Tafel slopes showed that the added inhibitor blocked the MS surface, indicating an inactivation towards corrosion and suggesting geometric blocking effect [25]. Moreover the addition of AY15 inhibitor indicates that the molecules of the inhibitor adsorbed on the MS surface [26] thereby reducing the polarization of the MS specimen i.e. reduces the conversion of the metal into metal ions.

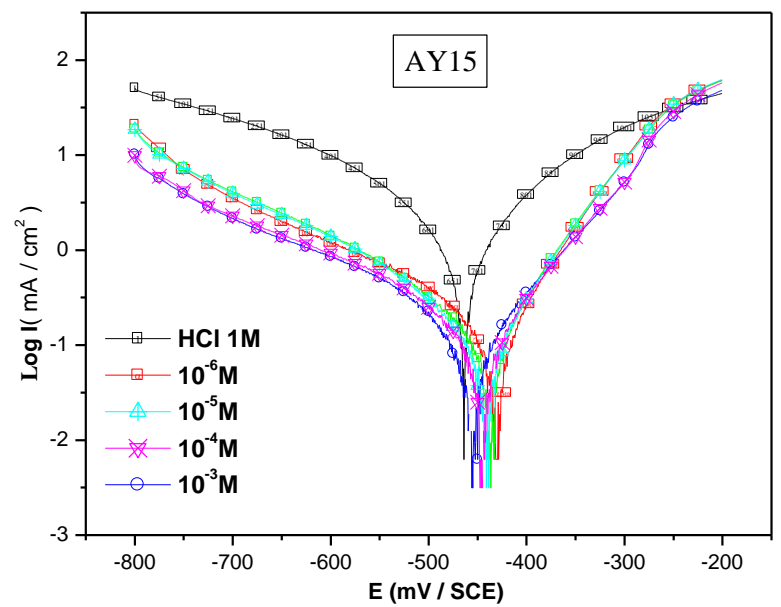

Figure 4. Tafel plot of MS in $1.0 \mathrm{M} \mathrm{HCl}$ solutions without and with different concentrations of AY15 inhibitor.

Table 3. Tafel polarization parameters obtained for MS in $1.0 \mathrm{M} \mathrm{HCl}$ solutions without and with different concentrations of AY15 inhibitor.

\begin{tabular}{cccccc}
\hline $\begin{array}{c}\text { Inhibitor in } \\
\mathbf{1 . 0} \mathbf{M ~ H C l}\end{array}$ & $\begin{array}{c}\text { Concentration } \\
\text { of inhibitor }(\mathbf{M})\end{array}$ & $\begin{array}{c}-\boldsymbol{E}_{\text {corr }} \\
(\mathbf{m V} \mathbf{S C E})\end{array}$ & $\begin{array}{c}\boldsymbol{I}_{\mathbf{c o r r}} \\
\left(\boldsymbol{\mu} \mathbf{A} / \mathbf{c m}^{\mathbf{2}}\right)\end{array}$ & $\begin{array}{c}-\boldsymbol{\beta}_{\mathbf{c}} \\
\left(\boldsymbol{\mu} \mathbf{A} / \mathbf{c m}^{\mathbf{2}}\right)\end{array}$ & $\begin{array}{c}\boldsymbol{E}_{\mathbf{I}} \\
(\boldsymbol{\%})\end{array}$ \\
\hline- & - & 465 & 1386 & 164 & - \\
\hline \multirow{3}{*}{ AY15 } & $10^{-6}$ & 444 & 469 & 132 & 66 \\
& $10^{-5}$ & 446 & 391 & 164 & 72 \\
& $10^{-4}$ & 454 & 277 & 179 & 80 \\
& $10^{-3}$ & 459 & 132 & 181 & 90 \\
\hline
\end{tabular}




\subsubsection{Electrochemical Impedance Spectroscopy (EIS)}

The corrosion behavior of the MS in $1.0 \mathrm{M} \mathrm{HCl}$ solution in the absence and presence of AY15 was also examined by the EIS technique after half an hour of immersion of MS in $1.0 \mathrm{M} \mathrm{HCl}$ solution at $308 \mathrm{~K}$.

Figures 5 and 6 show the Nyquist and Bode plots that obtained for MS without and with AY15 inhibitor in $1.0 \mathrm{M} \mathrm{HCl}$ solutions at the open circuit potential. The corresponding fitted parameters are recorded in Table 4.

The Nyquist diagrams spectra have a single capacitive loop whose size increases with the increase of AY15 inhibitor concentration, this round means that a phenomenon occurs. In addition to that, this phenomenon indicates that the corrosion is controlled by a process of charge transfer, which acts on the variation of the double layer capacity. Furthermore, the addition of AY15 to the $1.0 \mathrm{M} \mathrm{HCl}$ solution leads to the increase of the dimension of the capacitive loops as the AY15 concentration increases in comparison with that observed in impedance diagram. As a result, the inhibition efficiency increases caused by adsorption of the AY15 on the MS surface [27, 28].

Table 4 shows that the values of $R_{\mathrm{ct}}$ increase by increasing concentration of AY15 inhibitor reaching a maximum value of $222.49 \Omega \cdot \mathrm{cm}^{2}$ at $10^{-3} \mathrm{M}$ concentration of the inhibitor AY15. This increase in $R_{\text {ct }}$ protects MS from corrosion and decreases the number of active sites that are hidden by the adsorption of the molecules of AY15 inhibitor on MS surface on top of the chloride ions that electrostatically attracted on the positively charged MS surface [29].

In addition, the values of the $C_{\mathrm{dl}}$ in the presence of AY15 inhibitor are lower in comparison with the uninhibited values. This can be attributed to the adsorption of the inhibitor AY15 on the MS surface leading to the formation of a protective layer [30].

The value of the $\omega_{\max }$ was found to be equal to $929.60 \mathrm{rad} \cdot \mathrm{s}^{-1}$ in $1.0 \mathrm{M} \mathrm{HCl}$ solution without AY15 inhibitor and $98.29 \mathrm{rad} \cdot \mathrm{s}^{-1}$ in $1.0 \mathrm{M} \mathrm{HCl}$ solution with $10^{-3} \mathrm{M}$ concentration of AY15. In addition, this behavior means that the charge rate at the MS-solution interface is highly reduced and that this inhibitor is well adsorbed on the surface of MS. In conclusion, the corrosion inhibition efficiency of AY15 increases with the increase of the increase in the concentration of the studied inhibitor reaching a value of $93 \%$ at $10^{-3} \mathrm{M}$ concentration of AY15.

The Bode diagrams of the MS in $1.0 \mathrm{M} \mathrm{HCl}$ solutions in the absence and presence of different concentrations of AY15 inhibitor are illustrated in Figure 6. From Bode diagrams, it is obviously noticed that the phase angles increasing with increasing of the concentration of AY15 inhibitor. This increase in phase angle confirms that the MS surface is highly protected by the AY15 inhibitor.

Equivalent circuits are generally used to explore EIS data [31,32]. A one-time constant electrical equivalent circuit (Figure 7) was utilized for modeling of impedance plots. In the model used the $R_{\mathrm{s}}, R_{\mathrm{ct}}$ and CPE are the solution resistance, charge transfer resistance and constant phase elementis used for a non-ideal double layer. 


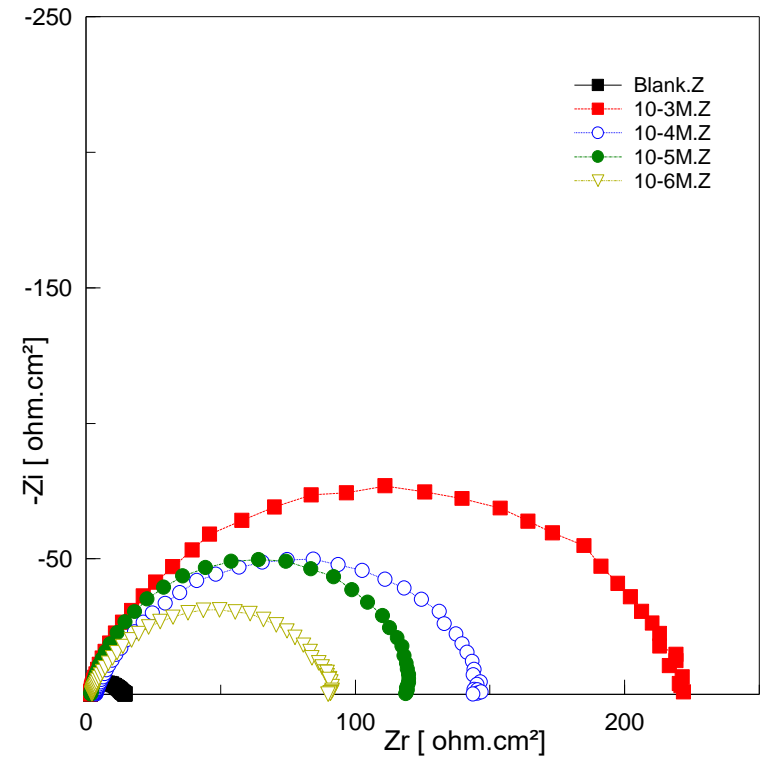

Figure 5. Impedance diagrams for the corrosion of MS in $1.0 \mathrm{M} \mathrm{HCl}$ solution without and with various concentrations of AY15 inhibitor at $308 \mathrm{~K}$.

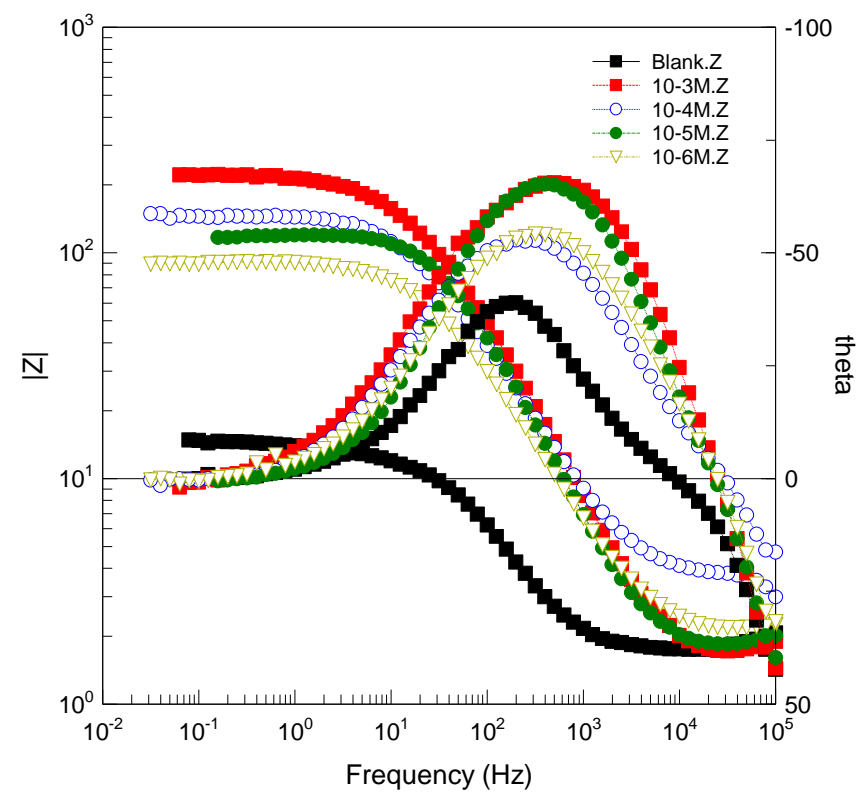

Figure 6. Electrochemical impedance Bode-Phase plots of MS in 1.0 M HCl solution without and with different concentrationsof AY15 inhibitor at 308K. 
Table 4. EIS parameters for the corrosion of $\mathrm{MS}$ in $1.0 \mathrm{M} \mathrm{HCl}$ solution without and with different concentrations of the inhibitor AY15 at $308 \mathrm{~K}$.

\begin{tabular}{|c|c|c|c|c|c|}
\hline \multirow{2}{*}{ Parameter } & \multicolumn{5}{|c|}{ Concentration of Inhibitor $(\mathrm{M})$ in $1.0 \mathrm{M} \mathrm{HCl}$} \\
\hline & - & $10^{-6}$ & $10^{-5}$ & $10^{-4}$ & $10^{-3}$ \\
\hline Real Center & 9.25 & 47.272 & 61.285 & 75.448 & 111.79 \\
\hline Image Center & 1.62 & 16.682 & 9.3015 & 25.355 & 40.647 \\
\hline Diameter & 15.13 & 96.147 & 119.66 & 151.71 & 235.85 \\
\hline$n$ & 0.81 & 0.39687 & 1.2307 & 1.1712 & 1.0249 \\
\hline $\begin{array}{l}\text { Low Intercept } \\
R_{\mathrm{S}}\left(\Omega \cdot \mathrm{cm}^{2}\right)\end{array}$ & 1.86 & 2.185 & 2.182 & 3.957 & 1.0952 \\
\hline $\begin{array}{c}\text { High Intercept } \\
R_{\mathrm{t}}\left(\Omega \cdot \mathrm{cm}^{2}\right)\end{array}$ & 16.64 & 92.358 & 120.39 & 146.94 & 222.49 \\
\hline Depression angle & 12.42 & 20.304 & 8.9437 & 19.528 & 20.163 \\
\hline$\omega_{\max }\left(\mathrm{rad} \cdot \mathrm{s}^{-1}\right)$ & 929.60 & 172.43 & 212.23 & 123.43 & 98.299 \\
\hline Estimated $R_{\mathrm{t}}\left(\Omega \cdot \mathrm{cm}^{2}\right)$ & 14.78 & 90.173 & 118.21 & 142.98 & 221.39 \\
\hline Estimated $C_{\mathrm{dl}}\left(\mathrm{F} \cdot \mathrm{cm}^{-2}\right)$ & $7.11 \mathrm{E}-5$ & $6.0319 \mathrm{E}-5$ & $3.9377 \mathrm{E}-5$ & $5.3402 \mathrm{E}-5$ & $4.3134 \mathrm{E}-5$ \\
\hline$E(\%)$ & - & 83 & 87 & 90 & 93 \\
\hline
\end{tabular}

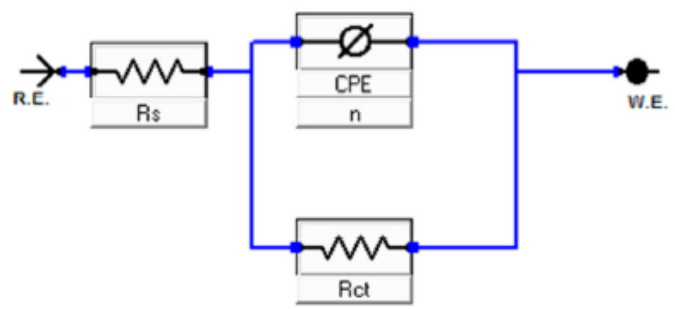

Figure 7. Equivalent circuit used to model metal/solution interface of $\mathrm{MS}$ in $1.0 \mathrm{M} \mathrm{HCl}$ solution in the absence and presence of AY15 inhibitor (for equivalent circuit diagram, $R_{\mathrm{S}}$ : uncompensated solution resistance, $R_{\mathrm{ct}}$ : charge-transfer resistance and CPE: constant phase element.

\section{Theory and computational details}

In order to compare the experimental and theoretical results, a theoretical study was carried out using the Gaussian program. Ionization potential (I) and electron affinity (A) are related to $E_{\mathrm{HOMO}}$ and $E_{\mathrm{LUMO}}$ as follows $[33,34]$ :

$$
I=-E_{\mathrm{HOMO}}, A=-E_{\mathrm{LUMO}}
$$

The approximated equation for the absolute electronegativity $(\chi)$ and global hardness $(\eta)$ of the inhibitor molecule is as follows [35]: 


$$
\begin{gathered}
\chi=\frac{I+A}{2}, \chi=-\frac{1}{2}\left(E_{\mathrm{HOMO}}+E_{\mathrm{LUMO}}\right), \\
\eta=\frac{I-A}{2}, \eta=-\frac{1}{2}\left(E_{\mathrm{HOMO}}-E_{\mathrm{LUMO}}\right)
\end{gathered}
$$

To evaluate the electronic flow in the reaction of too systems with different electronegativities, in this particular case; a metallic surface Fe and an inhibitor molecule of AY15 were assumed for the calculation of the fraction of transferred electrons $\Delta N$ according to Pearson theory [36]. $\Delta N$ is given by the following equation:

$$
\Delta N=\frac{\chi_{F e}-\chi_{i n h}}{2\left(\eta_{F e}+\eta_{i n h}\right)},
$$

where:

$\chi_{\mathrm{Fe}}:$ Absolute electronegativity of an iron atom $(\mathrm{Fe})$;

$\chi_{\text {inh }}$ : Absolute electronegativity of inhibitor molecule;

$\eta_{\mathrm{Fe}}$ : Absolute hardness of Fe atom;

$\eta_{\text {inh }}$ : Absolute hardness inhibitor molecule.

The global electrophilicity index was introduced by Parr [37] as a measure of energy lowering due to maximal electron flow between donor and acceptor and is given by

$$
\omega=\frac{\chi^{2}}{2 \eta}
$$

The softness $\sigma$ the inverse of the $\eta$ [38], and it can be represented in the following equation:

$$
\sigma=\frac{1}{\eta}
$$

\subsection{Quantum chemical calculations}

HOMO and LUMO are very important for describing chemical reactivity. The HOMO represents the ability $\left(E_{\mathrm{HOMO}}\right)$ to donate an electron, whereas, LUMO as an electron acceptor, represents the ability ( $\left.E_{\mathrm{LUMO}}\right)$ to obtain an electron. The energy gap between HOMO and LUMO determines the kinetic stability, chemical reactivity, optical polarizability and chemical hardness-softness of a compound [39]. In this paper, the HOMO and LUMO orbital energies were calculated using B3LYP method with 6$31 \mathrm{G}(\mathrm{d}, \mathrm{p})$. All other calculations were performed using the results with some assumptions. The higher values of $E_{\text {Номо }}$ indicate an increase for the electron donor and this means a better corrosion inhibition efficiency with increasing adsorption of the inhibitor molecules on the MS surface, whereas $E_{\mathrm{LUMO}}$ indicates the ability to accept electrons of the inhibitor molecule from the MS surface. The adsorption ability of the inhibitor to the metal surface increases with increasing of $E_{\mathrm{HOMO}}$ and decreasing of $E_{\mathrm{LUMO}}$. The HOMO and LUMO 
orbital energies, energy gap, electrophilicity and chemical hardness-softness values were obtained and tabulated in Table 5. The high ionization energy values for the inhibitor $(I=$ $5.92 \mathrm{eV}$ ) indicate high stability.

Table 5. Quantum chemical descriptors of the studied inhibitor at B3LYP/6-31G.

\begin{tabular}{cc}
\hline Parameters & Value \\
\hline Total energy $T E(\mathrm{eV})$ & -32573.8 \\
$E_{\text {HOMO }}(\mathrm{eV})$ & -5.9209 \\
$E_{\mathrm{LUMO}}(\mathrm{eV})$ & -1.5055 \\
Gap $\Delta E(\mathrm{eV})$ & 4.4154 \\
Dipole moment $\mu($ Debye $)$ & 6.3170 \\
Ionisation potential $I(\mathrm{eV})$ & 5.9209 \\
Electron affinity $A$ & 1.5055 \\
Electronegativity $\chi$ & 3.7132 \\
Hardness $\eta$ & 2.2027 \\
Electrophilicity index $\omega$ & 3.1227 \\
Softness $\sigma$ & 0.4530 \\
Fractions of electron transferred $\Delta N$ & 0.7444 \\
\hline
\end{tabular}

The number of transferred electrons from the inhibitor to the metal $(\Delta N)$ was also calculated. The $\Delta N<3.6$ indicates the tendency of a molecule to donate electrons to the metal surface [40]. As mentioned above, inhibition efficiency and $\Delta N$ are highly correlated. Hence, the higher inhibition efficiency of AY15 is in good agreement with the increased $\Delta N$ values $(0.7444)$.

The final optimized geometry of AY15 is shown in Figure 8.

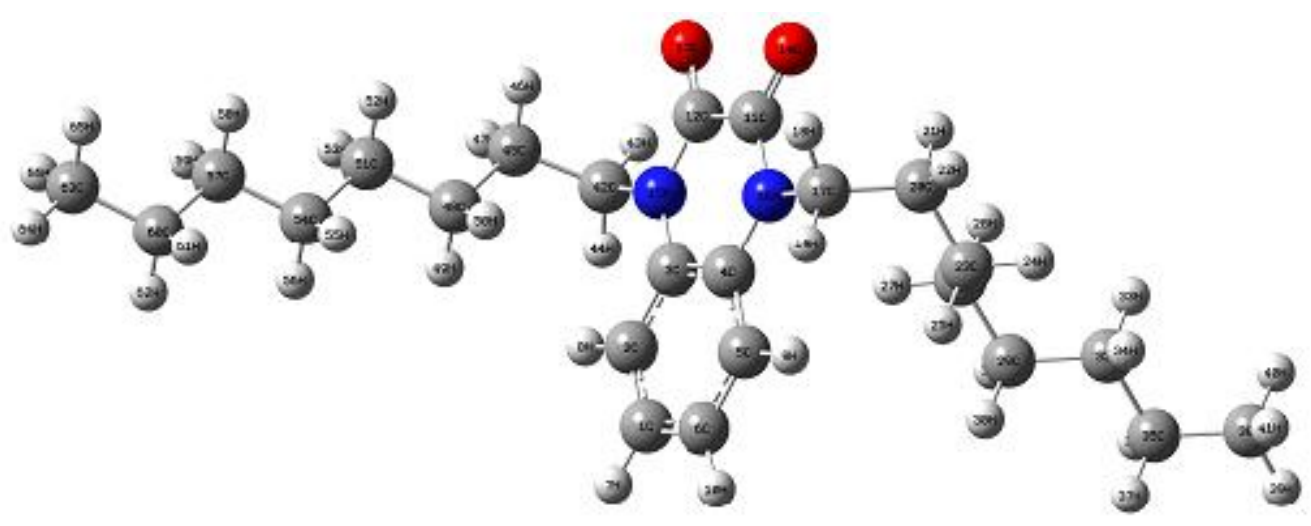

Figure 8. Optimized molecular structure of AY15 calculated at B3LYP/6-31G level. 


\section{Conclusion}

1,4-Dioctyl-6-methyl-1,4-dihydroquinoxaline-2,3-dione AY15 was found to be an efficient corrosion inhibitor for $\mathrm{MS}$ in $1.0 \mathrm{M} \mathrm{HCl}$ solution. Polarization studies showed that AY15 is a mixed type inhibitor and its corrosion inhibition efficiency increases with the increase in the concentration of the inhibitor. Impedance method indicates that the molecules of AY15 adsorb on the MS surface with increasing transfer resistance and decreasing of the double-layer capacitance. The adsorption of AY15 on the MS surface obeys Langmuir adsorption isotherm with high correlation coefficient. The adsorption process is a spontaneous and exothermic process. The corrosion inhibition efficiency values were determined by electrochemical and gravimetric methods. It is found that the values are in good agreement. DFT calculations demonstrated that the active sites of the molecules of AY15 are the nitrogen atoms and the methyl group.

\section{References}

1. A. Dell, D.H. William, H.R. Morris, G.A. Smith, J. Freeney and G.C.K. Roberts, J. Am. Chem. Soc., 1975, 97, 2497.

2. C. Bailly, S. Echepare, F. Gago and M.J. Waring, Anti-Cancer Drug Des., 1999, 15, 270.

3. R.H. Bahekar, M.R. Jain, A.A. Gupta, A. Goel, P.A. Jadav, D.N. Patel, V.M. Prajapati and P.R. Patel, Arch. Pharm. (Weinheim, Ger.), 2007, 340, 359-366.

4. H.M. Refaat, A.A. Moneer and O.M. Khalil, Arch. Pharmacal Res., 2004, 27, $1093-$ 1098.

5. S.A.M. EI-Hawash and A.E. Abdei-Wahab, Arch. Pharm. (Weinheim, Ger.), 2006, 339, 437-447.

6. M. Loriga, S. Piras, P. Sanna and G. Parlietti, Farmaco, 1997, 52, 157-166.

7. Ya.G. Avdeev, Int. J. Corros. Scale Inhib., 2018, 7, no. 4, 460-497. doi: 10.17675/2305-6894- 2018-7-4-1

8. H. Elmsellem, T. Harit, A. Aouniti and F. Malek, Prot. Met. Phys. Chem. Surf., 2015, 51, 873-884.

9. D. Jeroundi, S. Chakroune, H. Elmsellem, E.M. ElHadrami, A. Ben-Tama, A. Elyoussfi and B. Hafez, J. Mater. Environ. Sci., 2017, 5, 1116-1127.

10. S. Lahmidi, A. Elyoussfi, A. Dafali, H. Elmsellem, N.K. Sebbar, L. El Ouasif, A.E. Jilalat, B. El Mahi, E.M. Essassi, I. Abdel-Rahman and B. Hammouti, J. Mater. Environ. Sci., 2017, 8, 225.

11. M. Khasanah, H. Darmokoesoemo, L. Kustyarini, Y. Kadmi, H. Elmsellem and H.S. Kusuma, Results Phys., 2017, 7, 1781-1791. doi: 10.1016/j.rinp.2017.05.015

12. Z. Tribak, Y. KandriRodi, H. Elmsellem and I. Abdel-Rahman, J. Mater. Environ. Sci., 2018, 9, 334-344.

13. H. Elmsellem, N. Basbas, A. Chetouani and A. Aouniti, Port. Electrochim. Acta, 2014, 2, 77-108. 
14. H. Elmsellem and K. Karrouchi, Pharma Chem., 2015, 7, 237-245.

15. G. Aziate, H. Elmsellem, N.K. Sebbar and Y. ElOuadi, J. Mater. Environ. Sci., 2017, 8, 3873-3883.

16. H. Elmsellem, A. Aouniti, H. Bendaha, T. Benhadda, A. Chetouani and I. Warad, Phys. Chem. News, 2013, 70, 84.

17. H. Bendaha, H. Elmsellem, A. Aouniti, M. Mimouni, A. Chetouani and B. Hammouti, Physicochem. Mech. Mater., 2016, 1,111-118.

18. S. Attabi, M. Mokhtari, Y. Taibi, I. Abdel-Rahman, B. Hafez and H. Elmsellem, J. Bio. Tribo. Corros., 2019, 5, 2. doi: 10.1007/s40735-018-0193-5

19. R. Chadli, M. Elazouzi, I. Khelladi, A.M. Elhourri and A. Aouniti, Port. Electrochim. Acta, 2017, 35, 65-80.

20. M.Y. Hjouji, H. Steli, M.Y. Hjouji， M. Djedid, H. Elmsellem, Y. Kandri Rodi, M. Benalia, H. Steli, Y. Ouzidan, F. Ouazzani Chahdi, E.M. Essassi and B. Hammouti, Pharma Chem., 2016, 8, 85-95.

21. A. Aouniti, H. Elmsellem, S. Tighadouini, M. Elazzouzi, S. Radi, A. Chetouani, B. Hammouti and A.Zarrouk, J. Taibah Univ. Sci., 2015, 11, 008. doi: 10.1016/j.jtusci.2015.11.008

22. H. Elmsellem, M.H. Youssouf and A. Aouniti, Russ. J. Appl. Chem., 2014, 8, 744-753.

23. A. Elyoussfi, A. Dafali, H. Elmsellem and H. Steli, J. Mater. Environ. Sci., 2016, 7, 3344-3352.

24. K.R. Ansari, S. Ramkumar, D.S. Chauhan, Md. Salman, D. Nalini, V. Srivastava and M.A. Quraishi, Int. J. Corros. Scale Inhib., 2018, 3, 443-459. doi: 10.17675/23056894-2018-7-3-13

25. I. Chakib, H. Elmsellem, N.K. Sebbar, S. Lahmidi, A. Nadeem, E.M. Essassi, Y. Ouzidan, I. Abdel-Rahman, F. Bentiss and B. Hammouti, J. Mater. Environ. Sci., 2016, 7, 1866.

26. C. Verma, E.E. Ebenso and M.A. Quraishi, Int. J. Corros. Scale Inhib., 2018, 7, no. 4, 593-608. doi: 10.17675/2305-6894-2018-7-4-8

27. R.G. Pearson, J. Am. Chem. Soc., 1988, 110, 7684-7690.

28. M. Filali, E.M. El Hadrami, A. Ben-tama, B. Hafez, I. Abdel-Rahman, A. Harrach, H. Elmsellem, B. Hammouti, M. Mokhtari, SE. Stiriba and M. Julve, Int. J. Corros. Scale Inhib., 2019, 8, no.1, 93-109. doi: 10.17675/2305-6894-2019-8-1-9

29. I.B. Obot, N.O. Obi-Egbedi and S. Umoren, Adsorption Characteristics and Corrosion Inhibitive Properties of Clotrimazole for Aluminium Corrosion in Hydrochloric Acid, Int. J. Electrochem. Sci., 2009, 4, 863-877.

30. A. Zouitini, Y.K. Rodi, H. Elmsellem and H. Steli, J. Mater. Environ. Sci., 2017, 8, 4105.

31. H. Ju, Z.-P Kai and Y. Li, Corros. Sci., 2008, 50, 865-871.

32. H. Elmsellem, H. Nacer, F. Halaimia, A. Aouniti, I. Lakehal, A. Chetouani and B. Hammouti, Int. J. Electrochem. Sci., 2014, 9, 5328-5351.

33. R.G. Pearson, J. Am. Chem. Soc., 1988, 23, 7684-7690. 
34. Z.E. Adnani, M. Mchari, M. Sfaira, M. Benzakour, A.T. Benjelloun and M.E. Touhami, Corros. Sci., 2013, 68, 223-230.

35. I.B. Obot and N.O. Obi-Egbedi, Corros. Sci., 2010, 52, 657-660.

36. A. Rauk, Orbital Interaction theory of Organic Chemistry, $2^{\text {nd }}$ edition, John Wiley \& Sons, New York, NY, USA, 2001.

37. R.G. Parr, L.V. Szentpály and S. Liu, J. Am. Chem. Soc., 1999, 121, 1922-1924. doi: $\underline{10.1021 / j a 983494 x}$

38. P. Udhayakala, T.V. Rajendiran and S. Gunasekaran, J. Chem. Biol. Phys. Sci. A, 2012, 2, 1151-1165.

39. S. Kumar, D.G. Ladha, P.C. Jha, and N.K. Shah, Int. J. Corros., 2013, 10, 819643. doi: $\underline{10.1155 / 2013 / 819643}$

40. H. Ju, Z.-P. Kai and Y. Li, Corros. Sci., 2008, 50, 865-871. 